\title{
Affect of Play on Critical Thinking: What are the Perceptions of Preservice Teachers
}

\author{
Wirawani binti Kamarulzaman
}

\begin{abstract}
A lot of research suggested that children learn through play and their ability to think increases while playing. However it is not clear whether or not preservice teachers are aware of the influence of play on thinking. The purpose of the study is to explore the perceptions of preservice teachers on the affect of play on critical thinking, and how they perceive the current curriculum in terms of helping children to be critical thinkers. Interviews were conducted to two informants who are still studying in the Early Childhood Studies program in a private university in Klang Valley. The data was transcribed and coded and a few themes emerged from the transcriptions and coding processes. Findings suggested that those preservice teachers are sentient of the importance of play in cultivating critical thinking skills in children. They agreed that children learn through play and they construct knowledge while playing.
\end{abstract}

Index Terms-Critical thinking, children, learn trough play, preservice teachers, qualitative method.

\section{INTRODUCTION}

From early childhood through adolescence, children's cognitive functioning changes greatly. Social and intellectual activities need a great deal of cognitive functioning. During social interactions, assumptions about others' thoughts guide children's actions and frame their interpretations of others' actions. Children also form concepts of the nature of knowledge that contributes to the abilities to reflect on one's thought processes and evaluate the reasoning of others [1]. These abilities are important for critical thinking. Then the question is what is critical thinking? Critical thinking is the ability to make sound decision and problem solving [2]. A key component of critical thinking is the ability to evaluate the statements of other people [3]. Furthermore, one of the basic concepts of critical thinking being able to understand or figure out what the problem (or conflict, contradiction) is and to direct thinking to the specific purpose of solving the problem [4].

A research done by Lai [5] suggested that there are a few definitions of critical thinking based on various perspectives. According to her, in the philosophical approach, as philosophers such as Socrates, Plato, Aristotle, Matthew Lipman and Richard Paul, has focuses on hypothetical approach of critical thinkers, itemising a qualities and characteristics of a person, rather than behaviour or actions. They also focus on the qualities or standards of thoughts; for example, a good thinking should meet specified criteria or standards of adequacy and accuracy [5].

Manuscript received May 21, 2014; revised July 23, 2014.

Wirawani binti Kamarulzaman is with the Department of Early Childhood Studies, Universiti Tunku Abdul Rahman (email: tangwh@utar.edu.my).
Looking at the cognitive approach, Lai [5] emphasizes that it focuses on how people actually think versus how they could or should think under ideal conditions. Critical thinking includes a list of skills or procedures performed by critical thinker [5].

Bloom taxonomy is the base for educational approach to critical thinking. The benefit of educational approach, according to Lai [5] that, it based on observation and experiences of student learning. However, it has not been tested in depth as the philosophical and psychological approach [5].

Thinking process begins even before a child was born and the cognitive functioning of a child changes greatly from childhood to adolescence through social and intellectual activities. During social interactions, assumptions about others' thoughts guide children's actions and frame their interpretations of others' actions. Children also form concepts of the nature of knowledge that contributes to the abilities to reflect on one's thought processes and evaluate the reasoning of others, which also known as critical thinking [1].

Children begin thinking and learning as soon as they enter the world. By as early as age 3, children understand that people sometimes communicate inaccurate information and that some individuals are more reliable sources than others [3]. By 4 or 5 years of age, children also understand beliefs as representations that may be true or false [1]. Moreover, according to Pillow [1], although critical thinking curriculum is seldom included for preschool children, children are found to be able to think critically when the interact with their peers and adults [1].

One of the ways to develop critical thinking skills is through play. This is evidence through a research done by Holmes, Liden and Shin [6] who found that children's thinking styles has the influence on play and academic performance. Play is a way of doing things and considered as children's work [7]. Play is meaningful experience and it is also tremendously satisfying for children, a pursuit they seek out eagerly, and one they find endlessly absorbing [8]. Hewes [8] also found that play develops the foundation of intellectual, social, physical, and emotional skills necessary for success in school and in life. Lev Vygotsky (1896-1934) identified play as a leading source of development in terms of emotional, social, physical, language and cognitive. Recent scientific community also has recognise the benefits of play through exploration, experimentation and experiences can influence and advanced children's thinking skills, problem solving and language development [9].

Furthermore, children use play to actively construct knowledge, meet social/emotional needs and acquire skills 
[10]. This is congruent with research done by Jones and Reynolds [11] who suggested that "young children learn the most important things not by being told but by constructing knowledge themselves in interaction with the physical world and with other children - and the way they do this is by playing." (p. 1).

The below Table I simplify some of the things that children learn through play

TABLE I: WHAT CHILDREN LEARN THROUGH PLAY

\begin{tabular}{|l|l|}
\hline \multicolumn{1}{|c|}{ When children } & \multicolumn{1}{c|}{ They learn } \\
\hline Smile and coo at people & How to engage others in interaction \\
\hline Shake a rattle & Their actions produce results \\
\hline Throw toys on the floor & Principals of gravity; cause and effect \\
\hline Look at picture books & Pictures represent real objects \\
\hline Roll a ball & How to gain control of muscles \\
\hline Build with blocks & $\begin{array}{l}\text { Concepts of size, weight, symmetry, number } \\
\text { and balance; muscle control and coordination. }\end{array}$ \\
\hline
\end{tabular}

Moreover, Gordon [13] suggested that play encourages support among children and direct higher confidence level. Hewes [8] found that the intimacy and joy of friendship as children explore their own emerging identity creates self-directedness, and thus play leads to feelings of competence and self-confidence However, meaningful learning can only be achieved through teachers and parents' guides and scaffolding as Vygotsky proposed. A skilful teacher of young children is important to make play possible and helps children keep getting better and better at [8]. Proper toys and learning environment should be prepared prior to children's learning through play [10].

McBride and Cleland [14] found that students of high schools were resistance to learner-centred modes of instructions when previously have been passively receives information from teacher-centred modes of instructions. They believed that critical thinking skills and experiences should be taught to students in early years to prevent such problem [14]. Therefore, it is crucial to expose students to the skills in during early childhood and teachers are the main agents to cultivate such skills in students. Since Malaysia is upgrading its preschool teachers' competency, a lot of diploma and degree in early childhood studies is offered in the public and private colleges and universities. These preservice preschool teachers are trained teachers and expected to deliver what is learned in the tertiary level into practice once they are put into service in preschools and kindergartens. However before the preschool teachers could encourage critical thinking ability of children, their perceptions on how learning should occur in pre-school environment ought to be looked at. Therefore, the purpose of this study is to explore the perceptions of preservice teachers on the affect of play on critical thinking ability of children and also their perceptions on the curriculum available for preschool children, that is to what extent the curriculum is helping teachers to teach and children to think. The research question that is intended to be answered is:

1) What are the perceptions of preservice teachers on the affect of play to critical thinking?

2) What are the perceptions of pre-service teachers on the preschool curriculum?

\section{THEORETICAL FRAMEWORK}

The underlying theoretical framework under study is Lev Vygotsky (1935/1978) theory of Cognitive Development. He highlighted that socio-cultural context of cognitive development interacts with the brain's biological maturation [15]. According to Vygotsky, external world models the mind and knowledge is internalization of social activity. He believed that cognitive development is a process where children's mental ability is enhanced by mediation; that is the tools within organized social activities and language as the cultural form of mediation, to developed high mental processes. Fig. 1 illustrates the process.

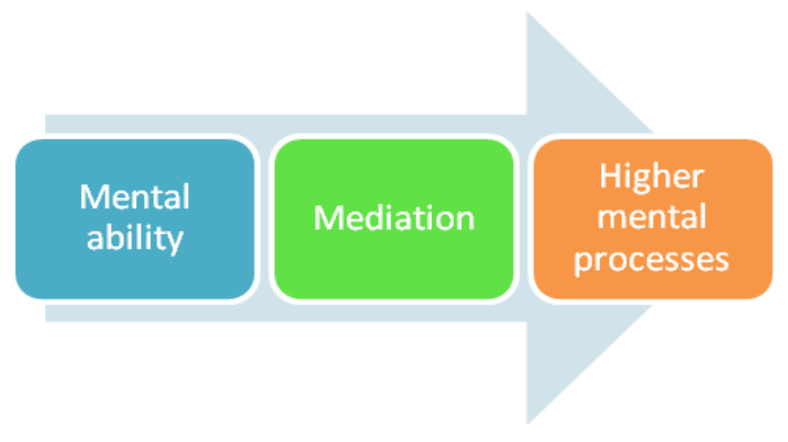

Fig. 1. Mental process.

Vygotsky suggested that children with certain mental ability, who could not solve any given problem due to his biological maturation, can actually solve the problem through interaction with other peers or adults and thus leads to higher mental processes [15].

\section{RESEARCH METHODOLOGY}

\section{A. Participants and Sampling Method}

Two preservice teachers who are still studying in their second year in the Early Childhood Studies program were employed as the informants for the study.

Purposive sampling method was employed in recruiting the informants. The power and logic of purposive sampling lies on the selecting information-rich cases so that the study could be done in depth [16].

\section{B. Design}

Interview guide approach was the form of interview approach used in the study. The approach suggested that the interviewer has an outline of topics or issue to be covered but is free to vary the wordings and order of the questions to some extent [17]. Semi-structured interview for in depth information was done for 30 to 45 minutes. Probing was done again and again to make sure saturation level met.

\section{Data Collection}

Data was collected from the answers to interview questions (IQ) which were derived from each research question (RQ) as follows:

1) What are some of the activities that can build critical thinking?

2) How can play cultivate critical thinking in children?

3) How play influence critical thinking?

4) What makes children think when they are playing? 
5) How the curriculum in NPCS contributes to critical thinking in children?

6) Do you think that the guidelines help children to think? How? Why?

\section{Data Analysis}

In the present study, the qualitative data analysis process was carried out in 5 steps. The recorded interviews were firstly transcribed verbatim. Then the main ideas were pulled out from the transcriptions. Subthemes were then developed from the main ideas and themes were recognized from the subthemes. The final step was to gather the inter-rater reliability measure. Generating themes is the most difficult, complex and ambiguous task but at the same time it can also be creative and fun [17]. The author can be proud after the process since the data is owned by the author herself from her own intellectual work!

In order to ensure the trustworthiness of the data, a few randomly selected themes were given to two raters to check their consistency. Selected pools of themes with the interview questions and discourse units were sent for inter-rater reliability check. The raters were selected based on their knowledge content of the research and their experiences working with children. It was found that the score for inter-rater check in the study is $73.7 \%$ indicates that the themes are fairly credible and trustworthy to suggest findings.

\section{RESUlTS AND DisCUSSION}

A few themes emerged from the interview. Analysis of the interview revealed the findings below.

\section{A. Free Play}

The first theme that appears was free play. The study suggested that free play may enhance critical thinking. The participant mentioned it again and again on the space and freedom to play for children in order to make them critical thinkers:

"Hmm...some free, maybe free play or free...let them, I think it's the space for them [children] is very important...the space I mean it's like...the...how far they can think."

One of the effects of not giving children the space to think, they would eventually develop the sense of accepting what their teachers say. When children just accept blindly without questioning, their development of critical thinking is slowed down [18].

\section{B. Learn Through Play}

Play is meaningful experience. It is also tremendously satisfying for children, a pursuit they seek out eagerly, and one they find endlessly absorbing [8]. The study found that children develop critical thinking ability through play. Play, according to the informant, constructs knowledge although children could not express their knowledge that their gained through playing yet children are learning through play.

"Because when they play, they actually aa...construct knowledge...they can learn a lot of things from play but even...even though it's not expressed out but then they will know."

As this in line with a proposition by Jones and Reynolds [11] that "young children learn the most important things not by being told but by constructing knowledge for themselves in interaction with the physical world and with other children - and the way they do this is by playing."(p.1). Another study also suggested that play develops the foundation of intellectual, social, physical, and emotional skills necessary for success in school and in life [8]. Play also encourages exploration. As Informant 1 alleged:

"And when they play, they will enjoy, and they will explore and that's when they learn and to be more...to think more and leads to critical thinking."

When children explore, they will build the skill of contrasting and comparing which are the characteristics of critical thinking as mentioned in first research question.

\section{Interaction}

Play also promotes interaction among children and adults. Play teaches children to deal with friends. Dealing involves speaking and playing appropriately with their friends. Thus, they are learning about good and bad things in friendship.

"For example if they're playing with friends, their social development may be developed, they will think...they will learn how to speak."

Gordon [13] suggested that play encourages support among children and direct higher confidence level. Hewes [8] found that the intimacy and joy of friendship as children explore their own emerging identity creates self-directedness, and thus play leads to feelings of competence and self-confidence However, a skilful teacher of young children is important to make play possible and helps children keep getting better and better at it [8].

\section{Play is Children's Work}

Play in addition found to be the children's work as they spend much of their time playing. Play to children is a fun thing. Informant 1 also included watching TV as fun and she considered that as play, or passive play. She claimed the ability of children to think critically when they compare the scenes in the TV with their real life.

"Cause this play this very big part of their lives, they play every time, for them everything is playing, cause they don't know what is learning also, so what you teach them, they..they just learn even like storytelling for them is like playing, watching television is like something fun bit those..aaaa.......that other...aaa...is, I mean like not TV program that is not beneficial for learning but TV programs that beneficial for learning for them is something, it's a game also, it's fun so they will learn, they will like, when they watch also, they will compare, what's there, what they're watching and what's happening with their real life then they will compare, maybe they will ask questions when they're, they're asking questions, they are more a critical thinker."

This is unswerving to a study which proposed that play is found to be spontaneous to children. Children have the right to leisure, play and participation in cultural and artistic 
activities [13].

\section{E. Interest}

Finally the study found that the interest that children have while playing initiate thinking in them.

"Children like to play, so when they play, they will engaged in the activity so they will, if they're engaged, then they will think laa."

Being interested is shown by paying full attention and their engagement in their playing activities. Since they are giving so much interest in their play, it is directly link with thinking ability hence critical thinking can be better.

\section{F. Teaching Methods}

Curriculum as the education guideline is found to be helping teachers in teaching method. The standard guideline for Malaysia preschools is the National Preschool Curriculum Standard (NPCS). However, some of preschools are not adopting the curriculum as mentioned by one of the participants below

"Aaa...yes, because there are a lot of activities and it...covers actually almost every aspect of the...what children have to learn but the problem is most of the preschools are not...following that."

Thus, it was found that the relationship between NPSC and children's thinking is vague.

"But the preschools are the ones who are not really helping...cause some they don't really quite follow the NPCS."

As stated above, curriculum provides guidelines for teachers. Some of the activities are play-based, project-based and inquiry-based.

"Cause the guideline says it it's supposed to be like play-based, very project based, inquiry they have to do inquiry, they query, they have to find out things (DU 2-88)."

Moreover, the guidelines help teachers to prepare their lessons well. Teachers need to use the guidelines to be effective in teaching yet no direct teaching should involved in teaching the preschoolers. As previously mentioned, direct teaching is one of the challenges to critical thinking. In addition, the curriculum is only helping teachers to develop lesson plans that are suitable for critical thinking development but it does not help critical thinking skill in children directly, teachers need to be the effective mediators for the curriculum to be considered as assisting children to be critical thinkers.

"The guidelines is to help educators to plan activities, not helping the children to be critical thinker."

Teachers need to know the children's appropriate development and ways to be successful in teaching children to be critical thinkers.

"Teacher is more important because if the teachers have the right way to teach and the teachers know the milestone, all the development milestones, know what to teach the children, then they will meet eventually meet the guidelines, it's actually based on the teacher's experience, the teacher's knowledge."

Among the activities that would enhance critical thinking ability is differentiation. Since one of the characteristics of critical thinking is the ability to find similarities and differences between things, therefore, when children can differentiate texture, for example, between raw potato and cooked potato, critical thinking is developed.

"Science activities, you need to compare a lot, like ...before and after, for example potato."

"Before it cooked, I mean it's when, it's..the potato is raw, and when it's cooked, the texture is different, so when they touch it, they will know."

\section{TRANSFERABILITY}

Transferability is defined as the degree to which the findings are applicable or useful to theory, practice and future research [19]. It is found that the current study could be applied to the proposed theory mentioned earlier. The proposed theoretical framework suggested that cognitive development is a process where children's mental ability is enhanced by mediation; that is the tools within organized social activities and language as the cultural form of mediation, to developed high mental processes [15] (Fig. 2).

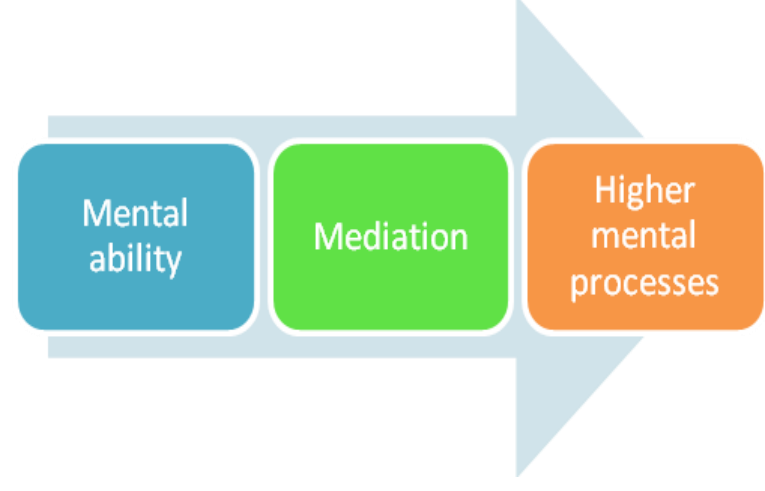

Fig. 2. Mental process

Transferability of themes to the theory (Fig. 3).

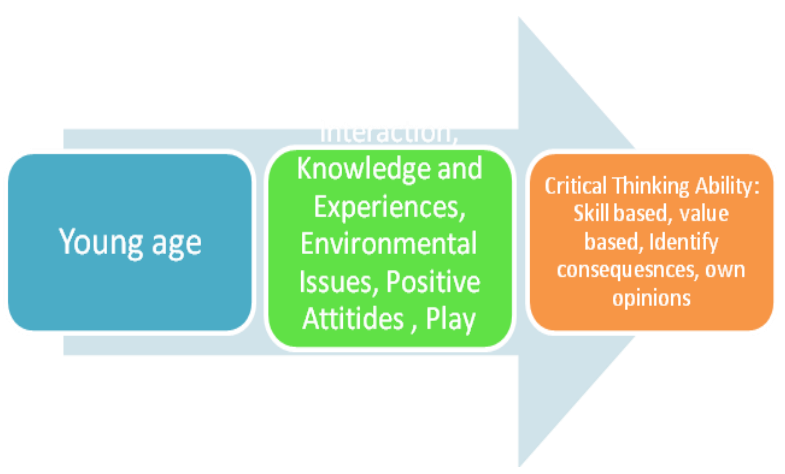

Fig. 3. Transferbility of themes into mental process

This is apparent that through social activities, that are interaction with adults and through play, children's critical ability is enhanced. Play is found to construct knowledge and as children spend much of their time playing, and that play becomes their work, they are building knowledge through 
exploration, experiences and experiments.

Environmental issues such as freedom and space to play also leads to critical thinking development. Positive attitudes of teachers who are supportive and initiation of suitable environment which involves the use of language as the cultural form of mediation also directs to critical thinking.

All of these mediators have contributed much in critical thinking ability in children where the current study found as ability based on skill and value. Besides, children learn to identify consequences and have their own opinions when they are able to think critically.

\section{CONCLUSION}

The study explores the perception of preservice teachers on influence of play on the critical thinking ability of children. The issue that brought upon the exploration is because a lot of research found that children are critical thinkers and they learn through play. However before the preschool teachers could encourage critical thinking ability of children, their perceptions on how learning should occur in pre-school environment ought to be looked at. Therefore it is crucial to know the perception of preservice teachers on the affect of play on children's thinking so that they will be able to put more hands-on activities and play to enhance critical thinking ability and how they perceive the national curriculum on its potentialities to help children to think critically.

The study employed two pre-service teachers who are still studying in their second year of bachelor degree program in Early Childhood Studies. The study was conducted in a private university in Klang Valley which took 20 to 30 minutes on interview session each.

Transcription was done after the interview. The verbatim was coded and themes were generated from the data. Inter-rater reliability score of $73.7 \%$ which indicate that the themes are credible and trustworthy enough to be presented as reliable for the study.

It was found that the participants agreed that children learn through play. They also construct knowledge as they play. Children learn to be critical thinkers through experiences in socialization with others and also supporting environment prepared for them by the adults.

Furthermore, play is considered as children's work as they spend much of their time to play. Work while playing makes children understand more of the world.

Play also seems to initiate thinking in children when they are interested in what they are playing. This would later leads to more thinking ability such as reflection, problem solving and decision making which are all considered as critical thinking skills.

Moreover, curriculum was found to be assisting teachers to create activities that promote critical thinking skills in children. Teachers should be able to monitor children's development so that proper teaching method and content could be applied. Teachers must not employ direct teaching or teacher-centeredness as this approach hampers critical thinking progress. It is important to note that curriculum built is for teachers to plan their lesson to inculcate critical thinking in children and curriculum by itself is meaningless when teachers are unable to make the full use of it.
It is hoped that this study may help teachers to improve their understanding on the needs of their students. Curriculum and teaching pedagogy may be enhanced to create better learning environment and cultivating critical thinking ability.

Finally, this study would fill in the gap in the literatures through qualitative approach. It will provide in depth analysis and insight of pre-service teachers on children's critical thinking ability.

\section{IMPLICATION FOR FUTURE RESEARCH}

It is found that children at pre-school age are able to think critically. However, environment may shape further development. Lack of freedom and direct teaching, as found in the study, indicated some barriers to critical thinking development.

Therefore, it is hoped that future research would put in more in depth exploration on factors that deters critical thinking development in children so that social ills and other social problem such as suicide could be managed better.

In addition to that, future research may recruit informants who are much closer to children that pre-service teachers who not yet have fully encountered with children. Perhaps in-service teachers would be a better choice for more evocative data.

Lastly, the current study found that play has a strong affect on critical thinking. Hence, future research may explore the kinds of teaching pedagogy that could be best adopted in schools to improve child-centeredness thus development of critical thinking ability could be improved.

\section{REFERENCES}

[1] S. Chen, B. Mulgrew, and P. M. Grant, "A clustering technique for digital communications channel equalization using radial basis function networks," IEEE Trans. on Neural Networks, vol. 4, pp. 570-578, July 1993.

[2] B. H. Pillow, "Development of children's understanding of cognitive activities," The Journal of Genetic Psychology, vol. 169, no. 4, pp. 297-321, 2008

[3] L. Mabe, The Importance of Applying Critical Thinking to Children's Learning, 2004

[4] G. D. Heyman, “Children's critical thinking when learning from others," Curriculum Dir Psychologicla Science, vol. 17, no. 5, pp. 344-347, 2010.

[5] J. D. Seaver, "Critical thinking in young children," Pro. Quest Dissertations and Theses, 1994.

[6] E. R. Lai, "Critical thinking: a literature review research report," Assessment and Information Group of Pearson, June, 2011.

[7] R. M. Holmes, S. Liden, and L. Shin, "Children's thinking styles, play and academic performance," American Journal of Play, vol. 5, no. 2, pp. 219-238. 2013.

[8] Learning and Developing through Play, Aister: the early childhood curriculum framework, n.d.

[9] B. J. Hewes, "Let the children play: Nature's answer to early learning," Early Childhood Learning, 2007.

[10] CMEC statement on play-based learning. (n.d.). [Online]. Available: http://www.cmec.ca/Publications/Lists/Publications/Attachments/282/ play-based-learning_statement_EN.pdf

[11] Toys, play and young children action guide. (n.d.). [Online]. Available: http://www.truceteachers.org/toyguides/T_Guide_web_09.pdf

[12] E. Jones and G. Reynolds, The Play's the Thing: Teachers' Roles in Children's Play, $2^{\text {nd }}$ Ed., New York: Teachers College Press, 2011.

[13] S. Botherson. (2009). What children learn through play. [Online]. Available: http://www.ag.ndsu.edu

[14] B. G. Gordon. (2003). What is play? In search of a universal definition. Play and Culture Studies. [Online]. Available: http://www.gwengordonplay.com/pdf/what_is_play.pdf 
[15] R. E. McBride and F. Cleland, "Critical thinking in physical education, putting the theory where it belongs; In the gymnasium," Journal of Physical Education, Recreation and Dance, vol. 69, no. 7, pp. 42-52. 1998.

[16] M. W. Passer and R. E. Smith, Psychology: The science of mind and behavior, $4^{\text {th }}$ Ed., New York: McGraw Hill Higher Education, 2008.

[17] I. T. Coyne, "Sampling in qualitative research. Purposeful and theoretical sampling; merging or clear boundaries?" Journal of Advanced Nursing, vol. 26, no. 3, pp. 623-630, 1997.

[18] N. S. N. A. Rahman, A Practical Guide to Interviewing in Educational Research, Selangor: Centre to Teaching and Learning, INSTEAD, IIUM, 2008.

[19] B. Bhaerman. (n.d.). Developing critical thinking skills in children. American Humanist Association. [Online]. Available: http://www.americanhumanist.org/What_We_Do/Education_Center/ HELP/2_Critical_Thinking/2.1_B/Developing_Critical_Thinking
[20] C. A. Lietz and L. E. Zayas, "Evaluating qualitative research for social work practitioners," Advances in Social Work, vol. 11, no. 2, pp. $188-202,2010$

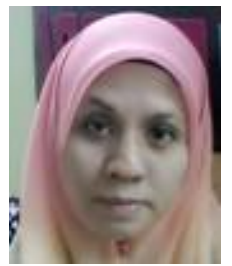

Wirawani binti Kamarulzaman is currently attached to Universiti Tunku Abdul Rahman as a lecturer in the Department of Early Childhood Studies of the Faculty of Creative Industries. Her bachelor degree was in human sciences majoring in psychology from International Islamic University Malaysia (IIUM). She did her master degree in educational psychology and currently she is pursuing her $\mathrm{PhD}$ in education from the same university. She has done a lot of research in educational psychology specifically on learning, learning styles, personality, critical thinking, motivation, stress, children's socio-emotional and children's drawing. Her research interests are children's critical thinking and learning 